\title{
Evidence levels in radiology: the insights into imaging approach
}

Luis Martí-Bonmatí ${ }^{*}$

Medicine is based on knowledge from scientific studies and the validation of clinical experience. Medical knowledge must be well established before it can be considered as the basis for decision making. Journals have a clear responsibility to help readers recognize the level of evidence for the claims published in their manuscripts. Levels of evidence alone do not determine the quality of the article but help readers to understand the significance of the claims.

We recognize that our discipline, radiology and medical imaging, also suffers from a certain lack of reproducibility of its results when translated into practice. Although our clinical work is firmly based on years of practice and well-known criteria and characteristics, new proposals and some older standards are not free of errors and biases.
This is the main reason why our journal encourages authors to follow this guideline when analyzing referenced papers and their own work (Table 1). The level and confidence in the evidence and the degree of consideration of the recommendations and their wordings are based on the type and quality of the references and the results of the paper. Authors are encouraged to specify in the manuscript the appropriate level and recommendation of their claims, following the criteria of this journal. The categorization into only three levels is based on publications in addition to critical approach to technical and clinical studies related to medical imaging [1-5]. These levels attempt to reconcile scientific knowledge and clinical certainty. We hope that this classification and grading will enlighten readers to better understand the relevance of published results and claims.

*Correspondence: eic@i3-journal.org

Hospital Universitario Y Politécnico La Fe, Valencia, Spain 
Table 1 Levels of evidence and recommendation

Levels of evidence and recommendation

\begin{tabular}{|c|c|c|}
\hline \multicolumn{2}{|c|}{ Level of evidence } & \multirow{2}{*}{$\begin{array}{l}\text { Confidence in the evidence and recommendations grade } \\
\text { Further research is unlikely to change our confidence in the estimate } \\
\text { of benefit and risk } \\
\text { Strongly recommended, mainly if presumed important patient } \\
\text { outcomes and/or acceptable costs } \\
\text { Wording associated with the High grade of recommendation: "must", } \\
\text { "should" "recommend" }\end{array}$} \\
\hline High & $\begin{array}{l}\text { Data derived from metanalyses or systematic reviews or from (multi- } \\
\text { ple) randomized trials with high quality } \\
\text { Large retrospective observational studies or in silico clinical trials } \\
\text { with external validation } \\
\text { Well defined reference standards and controlled biases } \\
\text { The described technique improves healthcare pathway (tests, treat- } \\
\text { ment, hospitalization) or decreases costs per patient } \\
\text { Level is graded down to Moderate if there are limiting biases or } \\
\text { inconsistencies between studies }\end{array}$ & \\
\hline Moderate & $\begin{array}{l}\text { Data derived from a single large randomized clinical trial or multiple } \\
\text { nonrandomized studies } \\
\text { Large retrospective observational multicentre studies or large in } \\
\text { silico clinical trials with controlled design and internal validation. } \\
\text { Appropriate spectrum of cases } \\
\text { Studies on technique assessments of noninferiority, surrogate } \\
\text { biomarkers or changes in clinical management } \\
\text { Level can be upgraded to High if there is a demonstrated large } \\
\text { effect size or downgraded if the effect size is small }\end{array}$ & $\begin{array}{l}\text { Further research is likely to have an impact on our confidence in the } \\
\text { estimate of benefit and risk and may change the estimate } \\
\text { Recommendation is modulated to strong or weak by the presumed } \\
\text { patient outcomes and final costs }\end{array}$ \\
\hline Low & $\begin{array}{l}\text { Small series, non-validated results and single centre observational, } \\
\text { experimental or technical studies } \\
\text { None or imperfect reference standards } \\
\text { No study on the validation of results } \\
\text { Large possible biases } \\
\text { Opinions, general statements, critical and educational reviews } \\
\text { without analytical methods } \\
\text { Studies on either technical efficacy or diagnostic validation accuracy } \\
\text { (reference standards) }\end{array}$ & $\begin{array}{l}\text { Any estimate of effect is uncertain } \\
\text { Weak recommendation, mainly if not clear patient important out- } \\
\text { comes and/or high cost } \\
\text { Wording associated with the Low grade of recommendation: "could", } \\
\text { "may","suggests" }\end{array}$ \\
\hline
\end{tabular}

\section{Authors' contributions}

This paper was written and revised by LMB. The author read and approved the final manuscript.

\section{Funding}

Not applicable.

\section{Availability of data and materials}

All relevant data are published in this Editorial.

\section{Declarations}

Ethics approval and consent to participate

Not applicable.

\section{Consent for publication}

Not applicable.

\section{Competing interests}

Luis Martí-Bonmatí is the Editor-in-Chief of Insights into Imaging. For this reason, he was not involved in any way in the revision/decision process, which was completely managed by the Deputy Editor, Prof. Bela Purohit (Singapore/ SG).
Received: 17 March 2021 Accepted: 26 March 2021

Published online: 07 April 2021

\section{References}

1. Guyatt GH, Oxman AD, Vist GE et al (2008) GRADE: an emerging consensus on rating quality of evidence and strength of recommendations. BMJ 336:924-926

2. Schweitzer ME (2016) Evidence level. J Magn Reson Imaging 43:543-543

3. Evidence-Based Radiology Working Group (2001) Evidence-based Radiology: a new approach to the practice of radiology. Radiology 220:566-575

4. European Association for the Study of the Liver (2018) EASL clinical practice guidelines: management of hepatocellular carcinoma. J Hepatol 69:182-236

5. Fryback DG, Thornbury JR (1991) The efficacy of diagnostic imaging. Med Decis Making 11:88-94

\section{Publisher's Note}

Springer Nature remains neutral with regard to jurisdictional claims in published maps and institutional affiliations. 